\title{
FIVE JAKOBSONIAN PRINCIPLES OF POETICS
}

ELMAR HOLENSTEIN

Bochum, West Germany

The painter Degas lamented the effort it took him to write poetry although he was "full of ideas". "Poetry is not made of ideas, my dear Degas," Mallarmé replied, "but of words" (Valéry 1965:1324). A more striking confirmation of the conception of poetry as propounded by Roman Jakobson is hardly conceivable. Slovo a slovesnost was the title of the bulletin published by the Cercle linguistique de Prague. The use of the Russian term for literature, slovesnost, an abstractive with the root slovo ('word') in combination with this same root slovo, was meant to point out the radical connection between language - for which slovo was understood to be a synecdochic designation-and poetry/literature and, in consequence, between linguistics and poetics/theory of literature. This explains Jakobson's descriptive rendition 'Word and Verbal Art', of the title he had also originally suggested for the Prague bulletin. He uses this same expression 'verbal art' with conspicuous, indeed offensive insistence in several headings of his poetic analyses. 'Verbal art' as well as the French art verbal are already becoming Jakobsonian neologisms in literary studies.

'Verbal art' is a program. Jakobson takes the language of the poet seriously. His approach to poetry is the approach of the linguist. There are, in the main, five principles upon which this linguistic conception of poetry is based.

1.

Fundamental to the poetic treatment of language is the "set towards the expression". This is the first, the phenomenological principle inasmuch as phenomenology is understood to be the

(c) American Journal of Semiotics, Vol. 2, No. 3 (1983), 23-34 
investigation of a datum, not as it (supposedly) is in itself, but as it appears with respect to the mode of apperception of the observer. The ordinary use of language as a means of reference, as the expression of experiences, as the appellation of a partner, etc. is thereby subordinated to the intrinsic value and autonomy of the linguistic medium as such. A poetic shaping of the linguistic medium shifts the focus from the objects that are referred to, from the feelings, emotions and desires that are expressed, to the medium itself. Even utterances at first sight held to be pure propaganda and information, become independent when poetically formulated, such as the paronomastic I like Ike coined for Eisenhower's election campaign or the simple iambic notice in a restaurant, In diesem Teil wird nicht serviert (literally: 'in this section no service'). Formulations of this kind, evidence of a subliminal poetic competence, strike a chord in our memories and survive long after they have lost their referential significance.

Russian Formalism initially responded to the 'object fetishism' of realistic literature by completely rejecting the referential aspect of poetic texts and focusing exclusively on the set towards the expression. A clear distinction must be made here between truth function (reference to a real world, no matter where or how, empirically or surrealistically, it is approached) and meaning function. The latter alone is inherent and essential to the linguistic sign. Thus, it alone can be expected to play an inalienable part in poetry as a holistic verbal art. Not the elimination, but the alienation of meaning alone was the purpose and also the effect of the deformation of the linguistic medium as practiced by the Futurists. However, the polemically one-sided thesis of eliminating reference to objects was subsequently modified. The set towards the linguistic medium as such does not eliminate its reference but rather makes it polyvalent. The phonetic and grammatical relations of similarity and contrast, the source of unity in a poem, involve shifts and superimpositions of meaning on the semantic level. Polyvalence or overdetermination is an inevitable consequence of a linguistic message that is centered upon itself.

2.

The set towards the expression is, for the recipient, the effect of the unusual organization of a linguistic utterance. For the poet, the relationship is inverted. The expectation with which he approaches 
language, transforms it first subjectively and then objectively as well. The most important transformation consists of the projection of the principle of similarity, which is constitutive of the paradigmatic axis of selection, onto the syntagmatic axis of combination, which in ordinary speech is characterized by the principle of contiguity. The thesis of the project of the principle of equivalence onto the axis of contiguity can well be designated as the structuralist principle. It recurs to one of the most central topics of European structural linguistics.

When we speak, we carry out two acts. We select linguistic units from a stockpile of equivalent units and combine them into a meaningful sentence. In the question, Who is wise enough to comprehend this?, we could, without changing the meaning of the sentence, select intelligent instead of wise and understand instead of comprehend. Expressions that can be reciprocally exchanged form paradigmatic families; the successive parts of discourse, who - is wise - etc., a syntagmatic chain. The poet projects the similarity groups of the paradigmatic axis onto the syntagmatic axis. The result in the example above is the simplest form of parallelism, a synonymous parallelism.

Who is wise enough to grasp these things?

Intelligent enough to understand them?

(Hosea, 14.10)

Similarity is frequently restricted to grammatical structure. The effect of syntactic parallelism is particularly striking if the parallel word categories do not merely differ in meaning but are in fact opposed to each other as contraries or contradictories.

Licht wird alles, was ich fasse,

Kohle alles, was ich lasse.

(Nietzsche, Ecce homo)

(Light becomes all I grasp,

Coal becomes all I leave.)

Nietzsche's parallelism (emphasis added) also illustrates the way in which the poetic device of syntactic parallelism, intensified by the antonymic opposition between the two paronomastic verbs fassen and lassen, insinuates a semantic shift in the two corresponding nouns. The metonymic relation of goal and means, of end and waste product, that exists between light and coal is antonymically transformed. Coal in 
Nietzsche's lines becomes a dark, solid, cold, earthly element diametrically opposed to the bright, airy, warm, heavenly light. Should the difference between two parallel expressions be more positive in nature, there ensues a metaphorical rather than an antonymic overdetermination of the metonymic relation.

Holt dein Blick mich noch ein, Holt dein Glück mich noch ein. (Nietzsche, Die Sonne sinkt)

(Should your look reach me, Your happiness will reach me.)

Every linguistic context has the effect of determining or even modifying meaning. The poet exploits this effect with purpose and plan.

Synonymic and antithetic parallelisms (this terminology stems from Robert Lowth, English Bible scholar of the 18th century) are the two elementary techniques whose manifold multiplication and modification make up a poem. Their multiplication is manifold inasmuch as they are active on all levels of language, the phonological, the grammatical and the lexical-semantic levels, both in the same and inverted order, thereby being repeated at irregular but not haphazard intervals, again in the same or inverted order. The most common forms of phonic parallelism are rhythm, rhyme and alliteration. In original poetry, standardized expectations, established by a technique of parallelism that has become commonplace, are frustrated by a surprising change or even only by a break. If the variation in the new work stands in an ordered relationship to its predecessors, the very sequence of old and new itself is experienced as an artistic whole.

The density and architectonic configuration of such parallelisms can be illustrated by taking any coherent fragment of a poem and, inasmuch as the poet himself does not already do so, arranging it in verse form. The example chosen below is the analysis, slightly abbreviated, of the rhyming words in Hölderlin's last poem, analyzed by Roman Jakobson with the assistance of Grete Lübbe-Grothues (Jakobson 1976:36f.). 


$\begin{array}{llll}\begin{array}{l}\text { rhyming } \\ \text { pairs }\end{array} & \begin{array}{l}\text { end of word/ } \\ \text { beginning of word }\end{array} & \text { stress } & \text { vowel length } \\ \text {-eben } & \text {-en } & \text { front vowel } & \text { long } \\ \text {-eben } & \text {-en } & \text { front vowel } & \text { long } \\ \text {-ilde } & \text { prefigured } & \text { front vowel } & \text { short } \\ \text {-ilde } & \text { only root } & \text { front vowel } & \text { short } \\ \text {-eiten } & \text {-en } & \text { front vowel } & \text { long (diphthong) } \\ \text {-eiten } & \text {-en } & \text { front vowel } & \text { long (diphthong) } \\ \text {-änzet } & \text { only root } & \text { front vowel } & \text { short } \\ \text {-änzet } & \text { prefigured } & \text { front vowel } & \text { short }\end{array}$

If we select a different letter for each feature, the following table results, whereby parts of the sequences that appear successively in the horizontal rows must be thought of as occurring simultaneously.
A E H I
A E H I
B F H K
B G H K
C E H J
C E H J
D G H K
D F H K

The projection of the relations of similarity and contrast from the paradigmatic axis onto the syntagmatic axis has an almost irresistable effect on the vertical arrangement of the dominant connecting lines in a graphic layout of the text. The dominant parallelisms find expression in the verses of the poem. Their repetition or systematic variation corresponds to the division into stanzas. Basically, the thesis of the projection of the principle of equivalence from the paradigmatic axis onto the axis of contiguity is nothing but a linguistic formulation and explication of that which is spontaneously expressed with the arrangement of a poem into verses and stanzas.

The third, the hermeneutic principle, has pertinence for the mutual dependence of the different linguistic levels. The part is to be 
understood in terms of the whole and the whole in terms of its parts. The semantic content of a poem can be extricated only in combination with a careful investigation of its phonological and grammatical shape. In applying the hermeneutic principle to the layered structure of language, Jakobson stands in marked contrast to another leading Hölderlin scholar, Martin Heidegger. In "Hölderlin und das Wesen der Dichtung," Heidegger tells us that "... language is essential as discourse alone. The remainder of what we designate as 'language', namely a stock of words together with rules for combining them, is only a foreground of language" (1971:38). What Heidegger, whose formation like that of Jakobson, is phenomenological and hermeneutic, dismisses in one sentence as mere "foreground of language," as a "stock of words together with rules for combining them," is Jakobson's leitfaden for interpreting the meaning of a poem. The poets are on Jakobson's side. Baudelaire: "Grammar, dry grammar itself becomes evocative sorcery" (quoted in Jakobson 1973:488). Hölderlin reciting is still plainer: Sehen Sie, gnädiger Herr, ein Komma! ['Look here, sir, a comma!'] (quoted in Jakobson 1976).

Even textbook poetics is wont to use paronomasia and rhyme as indices for semantic connections. It is Jakobson's particular and as yet insufficiently appreciated concern to go beyond the interdependence between the phonic and meaning levels by systematically exploring the interrelations between the grammatical and semantic strata. The transcript of the Louvain Lectures (1972) contains the following autobiographical comment.

Textbooks used to say that a poem can be deprived of its imagery, tropes and figures and still be a great poem because of its thoughts and feelings. When I started analysing some poems myself and compared those with their translation, I discovered that in the translations something was missing. Although the rhymes, the metre and the composition had been followed something remained absent and this absence destroyed the whole impression of the original. I understood that the grammatical structures of the original were missing in the translation, which meant to me that grammatical structures play a decisive role in poetry. They are a source of grammatical tropes and figures. (Van Ballaer 1973:1) 
An interpretation that ignores the phonic and grammatical shape of a poem and plunges directly into its supposed philosophical depths mutilates its message no less than a translation of a poem that disregards the phonic and grammatical character of the original. Every similarity in phonic form and in morphological-syntactic structure is brought into play by the poet with a view to the relation of similarity and/or contrast on the semantic level.

Despite poet's professions to the contrary, there are still those who question whether all the abstract linguistic categories and rules guiding linguist's analyses of poetry are also endowed with a psychic impact and reality, which haunt the poet and are subsequently sensed by the reader and listener. Isn't the linguist applying alien and sterile concepts to a work that ultimately resists rational and conceptual analysis? Psycholinguistic findings plainly demonstrate that the advocates of a linguistic poetics come closer to the subjective experience of language and the mode of its psychic reality than the champions of the mysterious moods and feelings beyond rational analysis that are supposedly conveyed by poetry. Association theory has long shown that associated words more often than not belong to the same word category as their stimuli. Similarly, reading mistakes made by patients suffering from alexia fall in the same category as the correct reading. Pronoun remains pronoun when an alexia patient reads 'our' instead of 'your'. A patient who stumbles over the word $E S$ 'it' and complains about those "horrid little words," although she can read the equally short substantive $E i$ 'egg' without hesitating, has somehow grasped that $E s$ 'it' belongs to the category of pronouns over which she always seems to stumble (Weigl and Bierwisch 1970:12). The mental reality of linguistic categories is most dramatically demonstrated by the common experience of 'tip-of-the-tongue' words. We are looking for a word that we are convinced we know. 'It's on the tip of our tongue' and yet we cannot pronounce it. Extraordinary here is the fact that, although the concrete substance of the word has escaped us, we are able to list abstract characteristics that are also the point of departure for linguistically oriented literary analyses. We know exactly, for instance, with what sound a person's name begins, how many syllables it has and what its prosodic pattern is ('a three-syllable word with the stress on the first syllable'); we know that it ends with a suffix morpheme and we even know which one (-mann), we know which ethnic groups it belongs to ('a Germansounding name') and what its semantic connotation is ('it has 
something to do with fear'). The accuracy of these criteria is asserted with astonishing confidence in checking suggestions made by the speaker himself or by others. The speaker is thoroughly convinced that the name he is looking for is neither Kurmann nor Käsemann, although he is by no means intuitively in command of the right name (Bangemann [bange $=$ 'afraid']). Some tip-of-the-tongue words are even candidates for the device of phonic-semantic inversion so cherished by structural poetics. At a dinner party someone wanted to say Forelle in English. The word trust occurred to him and he could not get it out of his mind. Although he knew perfectly well that this was not the right translation, he stubbornly insisted that trust had something to do with the missing expression. He was rescued by his neighbor who finally came up with trout. The meaning of the word trust corresponds to the (Swiss-)German trauen/er traut, whose phonic form coincides with the English term trout.

If abstract categories and structures prove to be guiding principles in speech disturbances caused by illness or ordinary fatigue, there is certainly justification in insisting that such categories and structures are also effective and palpable factors in the production and reception of poetic texts in which both author and reader are captivated by the linguistic medium as such. The 'tip-of-the-tongue' phenomenon is nothing but the prosaic brother of the poetic experience:

As many poets have said ... a poem begins with a musical phrase ringing insistently in the ears; at first inchoate, it later takes on a precise form, though still without words. I sometimes saw [Osip Mandelstam] trying to get rid of this kind of "hum", to brush it off and escape from it. He would toss his head as though it could be shaken out like a drop of water that gets into your ear while bathing. But it was always louder than any noise, radio or conversation in the same room ... At some point words formed behind the musical phrase and then the lips began to move... The whole process of composition is one of straining to catch and record something compounded of harmony and sense as it is relayed from an unknown source and gradually forms itself into words. The last stage of the work consists in ridding the poem of all the words foreign to the harmonious whole which existed before the poem arose. Such words slip in by chance, being used to fill gaps during the emergence of the whole. They 
become lodged in the body of the poem and removing them is hard work. (Mandelstam, 1970:70-71)

The hermeneutic principle of interpretation applies not only to the internal structure of a poem but also to its relationship with the poetic tradition to which it belongs or against which it rebels and further, to its affinity with the author's cultural, psychological and sociological background and his entire period. The position of a literary text in such increasingly comprehensive circles of phenomena is that of a part to a whole. Structuralism opposes the dilettantish and atomistic way in which isolated phenomena from diverse domains are linked together without first taking into account the systems in which they are embedded. This applies above all to poetic texts. Typical of texts in which the poetic function predominates over the other functions of language is a relative autonomy with regard to all these additional strata. Such a text is-to borrow from gestalt psychology a concept much valued by Jakobson-a Teilganzes 'partwhole'. It is a complete something that can be grasped in terms of itself alone, without reference to the author's life or the ideological trends of his time, which he may have shared or rejected.

4.

Kak delat' stixi 'How to make poems' is the title of an essay by Majakovskij; "What does a poet do with words?" of a Louvain lecture by Jakobson. Both titles are indicative of the fourth principle of Jakobsonian poetics, the constructivist principle. According to this principle, poetry is a kind of 'handicraft' which consists of the mastery of certain 'devices' selected according to the style and committment involved. The device most thoroughly explored by Russian Formalism was estrangement. A phonic mode of estrangement employed by Xlebnikov and also popular with children is that of exchanging the first letter of words, so that their meaning becomes blurred. Another technique is the use of unusual expressions in ordinary surroundings and, in reverse, the use of ordinary expressions in surroundings which have become the exclusive domain of elevated speech. In Prague Structuralism, violent deformations increasingly yield to transformational devices which are inherent to and generally constitutive of language, and which are systematically activated in poetry, in an artistic arrangement. For Jakobson, the predominant 
device exemplified by the manifold forms of parallelism and introduced here as the structuralist principle of the verbal art is the projection of the relations of similarity and contrast from the paradigmatic axis onto the syntagmatic axis.

The attunement of the verbal art to specifiable devices should not give rise to the illusion that textbooks and schools of poetry can teach us how to write poetry, like instructions for operating a new machine. The poetic application of these devices is largely subliminal, unconscious. Freud also describes the two major devices in the shaping of dreams, condensation and displacement, as two specifiable mechanisms and-metaphorically-as two "workshop masters", but does not thereby insinuate that the psychoanalyst with all his scientific insight is capable of the same achievements with which his patients daily surprise him. Furthermore, the condensation and displacement of the unconscious follow the same lines of association as those underlying the stylistic figures of metaphor and metonymy, which are in turn used by Jakobson to describe the two axes of language, the paradigmatic (metaphorical) and the syntagmatic (metonymic). The affinity between structuralist and psychoanalytical studies is primarily formal, in recurring to the same subliminally active structural laws, and not thematic in nature. The soul of man is not only a treasure chest of content-laden symbols, but foremost a stock of rules and structures, be they the onset of repression or an indispensable prerequisite for creative performance: anima naturaliter grammatica.

Jakobson has on occasion been charged with "idiosyncratic and catachrestic diction" (cf. the expression 'verbal art'). This may be more easily understood when also viewed as a legacy of the constructivism specific to Russian Futurism. Jakobson's starting point on his path toward literary and linguistic studies. Futurism recommended "organized violence" in the use of language to provoke new and unusual experiences.

5.

On closer inspection of the principles listed so far, it is curious to note that structural poetics meets with so much mistrust and misunderstanding in conservative circles. These principles are all backed by a tradition of long-standing. The last one is no exception, as demonstrated by the fact that the Russian Formalists themselves 
rendered the term priem 'device' with the time-honored technical expression in German Kunstgriff and also by the conspicuous adoption of classical, medieval, antique and even old Indian concepts (parallelism, metaphor, metonymy, brachyology, dipaka ['condensed expression'], etc.) to designate the various devices. What makes this approach to poetics offensively novel? Defensive reactions are apparently engendered by the fifth, the scientific principle, according to which the preceding principles are systematically applied instead of being treated casually as may be appropriate or even encouraged at a literary salon.

The widespread anti-scientific attitude toward literature and art rests above all on the confusion between two pairs of terms, on the confusion between 'structurally determinable' and 'exactly measurable' - the fact that so-called vague concepts such as 'big' and 'small' cannot be submitted to exact metrical measurement does not mean that they are concepts whose relationship to each other and to other concepts eludes all structural description-and on the still more superficial confusion between 'scientific' and 'infallible', as if the fallibility and revisability of all human knowledge were not a truism applicable to scientific scholarship as well.

The scientific principle is also a legacy of Futurism. Like its model, Cubism, Russian Futurism asserted the interdependence of art and art theory. Art itself, according to the anti-romantic and anti-symbolistic Futurist provocation, was the skilled application of transparent devices and was therefore to be treated and practiced as a science. This theory has led to the conviction that all creation is founded on a code, on a system of categories, rules and structures, and to the logical consequence of this line of thought, the conception of poetics as a rigorous science.

"I truly believe that a completely objective text analysis is possible, as far as an objective scientific interpretation in general is possible," Jakobson states in the above-mentioned Louvain Lectures. In the "Postscriptum" to his Questions de poétique (1973:488), in response to the reproach that he has missed "the subtle and elusive $I$ don't know what of which poetry is supposedly made," he states: "But this I don't know what proves equally elusive in the scientific investigation of language or society or the secrets of matter. The pompous opposition between the I don't know what and the inevitable approximation of the sciences is truly useless." 


\section{ELMAR HOLENSTEIN}

\section{NOTE}

1. Slightly revised translation of "Linguistische Poetik," introduction to Roman Jakobson, Hölderlin, Klee, Brecht, ed. by Elmar Holenstein. Frankfurt: Suhrkamp, 1976, 7-25. Translated by Catherine Schelbert.

\section{REFERENCES}

Heidegger, Martin

1971 "Hölderlin und das Wesen der Dichtung," in Erläuterungen $z u$ Hölderlins Dichtung. Frankfurt: Klostermann.

Jakobson, Roman

1973 Questions de poétique. Paris: Seuil.

1976 Hölderlin, Klee, Brecht. E. Holenstein, ed. Frankfurt: Suhrkamp. Reprinted in Selected Writings III. The Hague: Mouton.

Mandelstam, Nadezhda

1970 Hope Against Hope. New York: Atheneum.

Valéry, Paul

1965 Oeuvres I. Paris: Pléiade.

Van Ballaer, Marleen

1973 Aspects of the Theories of Roman Jakobson. Memoir, Universiteit Leuven (België): Fakulteit der Wijsbegeerten en Letteren (mimeograph).

Weigl, Egon and Bierwisch, Manfred

1970 "Neuropsychology and Linguistics," in Foundations of Language 6:12. 